\title{
Placental Fatty Acid Transfer: A Key Factor in Fetal Growth
}

\author{
Elvira Larquéa Ana Pagán ${ }^{a} \quad$ María Teresa Prieto $^{b}$ José Eliseo Blanco ${ }^{b}$ \\ Alfonso Gil-Sánchez $^{b}$ Matilde Zornoza-Moreno ${ }^{b}$ María Ruiz-Palacios $^{a}$ \\ Antonio Gázquez ${ }^{a}$ Hans Demmelmairc Juan José Parrillab ${ }^{\mathrm{b}}$ Berthold Koletzko ${ }^{c}$

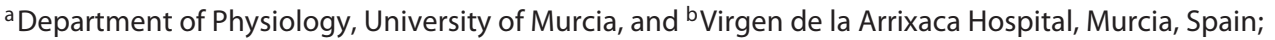 \\ 'Division of Nutrition and Metabolic Diseases, Dr. von Hauner Children's Hospital, Ludwig Maximilian \\ University of Munich, Munich, Germany
}

\section{Key Words}

Placenta · Fat · Long-chain polyunsaturated fatty acids · Insulin · Pregestational obesity

\begin{abstract}
The functionality of the placenta may affect neonatal adiposity and fetal levels of key nutrients such as long-chain polyunsaturated fatty acids. Fetal macrosomia and its complications may occur even in adequately controlled gestational diabetic (GDM) mothers, suggesting that maternal glycemia is not the only determinant of fetal glycemic status and wellbeing. We studied in vivo the placental transfer of fatty acids (FA) labeled with stable isotopes administered to 11 control and 9 GDM pregnant women (6 treated with insulin). Subjects received orally ${ }^{13} \mathrm{C}$-palmitic, ${ }^{13} \mathrm{C}$-oleic, and ${ }^{13} \mathrm{C}$-linoleic acids and ${ }^{13} \mathrm{C}$-docosahexaenoic acid $\left({ }^{13} \mathrm{C}\right.$-DHA) $12 \mathrm{~h}$ before an elective caesarean section. FA were quantified by gas chromatography and ${ }^{13} \mathrm{C}$ enrichments by gas chromatography-isotope ratio mass spectrometry. The ${ }^{13} \mathrm{C}-\mathrm{FA}$ concentration was higher in total lipids of maternal plasma in GDM patients versus controls, except for ${ }^{13} \mathrm{C}$-DHA. Moreover, ${ }^{13} \mathrm{C}$ DHA showed a lower placenta/maternal plasma ratio in GDM
\end{abstract}

patients versus controls and a significantly lower cord/maternal plasma ratio. Other FA ratios studied were not different between GDM and controls. A disturbed ${ }^{13} \mathrm{C}-\mathrm{DHA}$ placental uptake occurred in GDM patients treated with diet or insulin, while the latter also had lower ${ }^{13} \mathrm{C}$-DHA levels in the venous cord. The tracer study pointed towards an impaired placental DHA uptake as a critical step, while the transfer of other ${ }^{13} \mathrm{C}-\mathrm{FA}$ was less affected. Patients with GDM treated with insulin could also have a greater fetal fat storage, which may have contributed to the reduced ${ }^{13} \mathrm{C}-\mathrm{DHA}$ in the venous cord observed. The DHA transfer to the fetus was reduced in GDM pregnancies compared to controls. This might have an influence on fetal neurodevelopment and long-term consequences for the child.

(c) 2014 S. Karger AG, Basel

\section{Introduction}

The increasing prevalence of obesity in the world is resulting in an increasing number of obese women of reproductive age with an enhanced risk of developing gestational diabetes mellitus (GDM) during pregnancy. Both

\section{KARGER}

E-Mail karger@karger.com

www.karger.com/anm
(C) 2014 S. Karger AG, Basel

0250-6807/14/0644-0247\$39.50/0 
obesity and GDM are related to neonatal adiposity, and the placenta is a key organ mediating the materno-fetal nutrient transfer. The regulation of placental enzymes, receptors, and transport proteins determines the extent of glucose, lipid, and amino acid transfers to the fetus, which strongly contribute to fetal growth. Although improvements in prenatal care have significantly decreased the number of adverse outcomes, the mechanisms associated with fetal programming of obesity are under evaluation, and placental tissue could have a key role in the process of fetal growth and development.

\section{Perinatal Risk Factors for Fetal Overgrowth}

It is well recognized that maternal hyperglycemia plays an important role in the development of fetal macrosomia. The Pedersen hypothesis postulated that maternal hyperglycemia during pregnancy was transmitted to the fetus, which in turn produced and released large amounts of fetal insulin that promoted fetal overgrowth or macrosomia [1]. However, fetal macrosomia may occur even in adequately controlled GDM mothers $[2,3]$ and in offspring of obese women with a normal glucose tolerance $[4,5]$, suggesting that maternal glycemia is not the only determinant of fetal glycemic status and well-being.

Recent studies have reported that maternal pregestational obesity, even in women with well-controlled GDM, is also a very important determining factor for fetal growth and childhood obesity [6]. Nevertheless, the pregestational maternal body mass index (BMI) is not a biological effector, and the mechanisms via which the BMI exerts its effect on fetal growth remain largely unknown.

The maternal BMI may modify the supply of nutrients by affecting the insulin resistance, which may contribute to maternal dyslipidemia, and a higher availability of energy substrates may contribute to the enhancement of fetal fat transfer and deposition. Moreover, it may modify the cytokine and hormone environment, which may alter the placental structure and function, and it may even affect the placental nutrient transport capacity, impacting neonatal adiposity. In fact, the placental structure is altered in placentas of women with GDM, presenting notable increases in size and thickness $[7,8]$ which are well recognized by obstetricians; in obese subjects, an increase in placental size also occurs, especially in severely obese mothers [9].

In a multivariate analyses performed on healthy pregnancies from a subcohort $(n=207)$ of the STORK study in Norway, which focused on the determinants of fetal growth, it was shown that maternal BMI and fasting glucose were independently associated with the newborn fat percentage [10]. However, this effect disappeared when placental weight was introduced as a covariate. Those authors suggested that the effect of the maternal BMI on fetal fat accretion acts, to a significant extent, by modifying the placental weight [10].

In a further evaluation of the STORK cohort including 1,031 healthy pregnant women, the authors reported that the effect of maternal factors on placental weight was influenced by fetal sex; maternal glucose was significantly associated with placental weight in females but not in males [11]. Recently, fetal sex-specific differences in the placenta have been identified in terms of gene expression, histological examination, and cytokine production [12].

Thus, there is an emerging understanding of the physiology linked to sex-specific effects on the placenta. It is also interesting to note that gestational weight gain in early pregnancy (first half of the pregnancy) in such studies had a positive effect on placental weight. Maternal weight gain in early pregnancy is associated with a placental hormone-driven increase in plasma volume and fat stores, making the association between early weight gain and placental mass biologically plausible [11].

As in all healthy subjects, in normal pregnancies maternal insulin contributes to glucose homeostasis by improving the peripheral glucose tissue uptake. However, the role of insulin in placental glucose transfer is limited since placental glucose uptake occurs via the glucose transporter GLUT-1, the activity of which is independent of insulin [13].

However, placental tissue displays insulin receptors, and activation may lead to a cascade of signals which regulate the nutrient sensor signal mTOR (mammalian target of rapamycin) [14]. mTOR is a positive regulator of placental amino acid transporters and stimulates cell proliferation and growth, promoting an anabolic metabolic phenotype. Preliminary studies have indicated an activation of placental mTORC1 signaling in association with maternal obesity [15] and probably with GDM, which could be linked to higher insulin levels in these subjects. This could explain in part the greater size of GDM placentas compared to those of normoglycemic individuals. Insulin resistance also enhances maternal free fatty acids (FA) and triglycerides, particularly in obese individuals. In this context, it is important to consider whether factors other than glucose modulate fetal overgrowth and adiposity in overweight and obese women. 


\section{Placental Lipid Transport}

In normal pregnancies, during the third trimester there is a physiological insulin resistance that promotes maternal lipolysis, producing hyperlipidemia to ensure triglycerides and free FA for the fetus. In GDM pregnancies, this insulin resistance is exacerbated (fig. 1). Although, there are discrepancies, the lipid metabolism is altered towards a more atherogenic lipid profile, with high levels of triglycerides and low LDL cholesterol and reduced levels of HDL cholesterol [16]. A relationship between maternal triglycerides and nonesterified FA (NEFA) and fetal fat mass and neonatal body weight has been found in GDM, suggesting that an altered lipid metabolism is a risk factor for macrosomia in affected women [17].

In contrast to glucose, the role of lipids in the regulation of fetal growth has received little attention. The placental transfer of FA is a complex process that involves several lipases and FA carriers [18]. Lipid uptake requires the release of FA esterified within maternal lipoproteins. Lipoprotein lipase mainly hydrolyzes triglycerides, while endothelial lipase mainly hydrolyzes phospholipids, producing NEFA. The liberated FA (NEFA), as well as NEFA from the circulation, can be taken up by the placenta using FA carriers such as FA translocase (FAT/CD36), placental plasma membrane FA-binding protein ( $\mathrm{p}$ FABPpm), or FA transport proteins (FATP), a family of proteins comprised of 6 members known as FATP-1 to FATP-6. Once FA gain access to the cytosol, they bind to FA-binding proteins (FABP) and are thus transferred to the fetal circulation. FA can also be oxidized in the placenta or esterified in lipid fractions as, for example, triglycerides in lipid droplet structures [18].

Rat dams injected with 10 or $30 \mu \mathrm{g}$ radiolabel triglyceride $\left[{ }^{13} \mathrm{H}\right.$ olein] presented at $20 \mathrm{~min}$ postinjection the same relative percentage of dosed lipids taken up by the placenta for the higher as well as the lower dose. However, the relative percentage of dosed lipids transported to the fetus was lower in the dams given more lipids. Even though proportionately fewer lipids were transported to the fetus when more lipids were given, the absolute amount transported was still greater in the dams given the $30-\mu \mathrm{g}$ dose [19]. The maternal FA flux affects the placental lipid uptake, but the role of placental tissue in moderating this transfer remains to be clarified, especially in human studies.

In GDM compared to normoglycemic pregnancies, a higher accumulation of lipid droplets has been classically described in histological studies of placental tissue [20] and in trophoblast cells isolated using a density gradient

Placental Determinants of Obesity

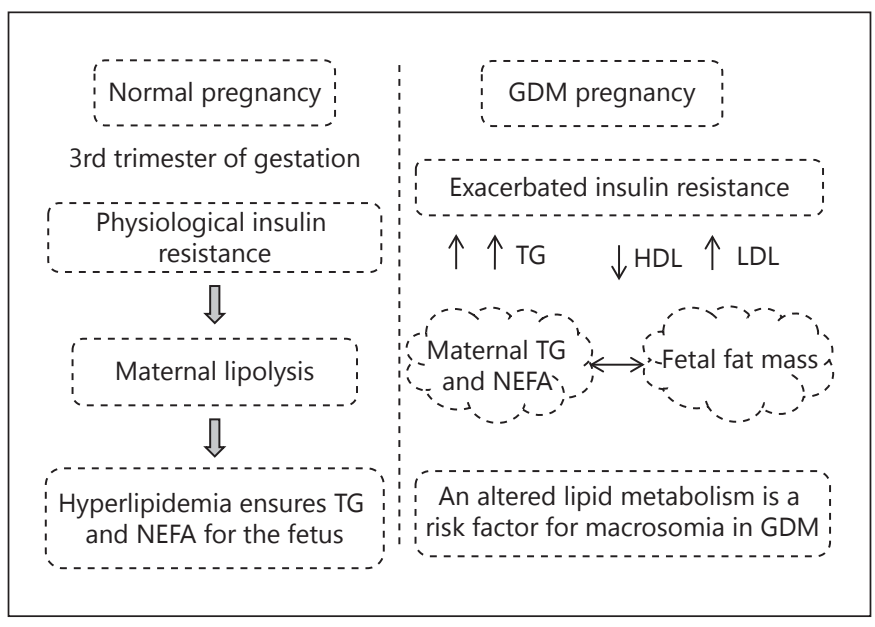

Fig. 1. Maternal lipid adaptations during the third trimester of pregnancy in healthy and GDM pregnancies. TG = Triglycerides.

[21]. However, quantification of lipids in the whole placenta is sometimes difficult because of contamination from blood. We recently reported a method to isolate placental lipid droplets for further FA analyses avoiding the problem of blood contamination [22]. A recent study using in vitro placental explants from healthy pregnancies and women with GDM reported that, in pregnancies with GDM, a shift in the flux of FA away from oxidation towards the esterification pathway may lead to the accumulation of placental triglycerides [23]. The mitochondrial FA oxidation rate was reduced by $\sim 20 \%$ in placentas from women with GDM, contributing to an enhanced triglyceride content within the placenta. Different cellular metabolization of FA in the placental trophoblasts might affect the transfer rate to the fetus; thus, a better knowledge of the intracellular metabolism could be of interest.

It is also important to consider that the functionality of the placenta may affect the fetal levels of key nutrients such as long-chain polyunsaturated FA (LC-PUFA), docosahexaenoic acid (DHA), or arachidonic acid. Nevertheless, the underlying mechanisms are still unknown. The placenta preferentially and selectively transports DHA as opposed to other FA, as we demonstrated in vivo in healthy pregnant women using FA labeled with stable isotopes [24]. This preferential transfer of LC-PUFA across the placenta highlights an important role of this organ in differential FA transfer to the fetus [24, 25]. However, an abnormal placental function, as occurs in GDM or intrauterine growth retardation, could disturb the materno-fetal LC-PUFA transport, with unknown consequences for the neurodevelopment of the offspring. 


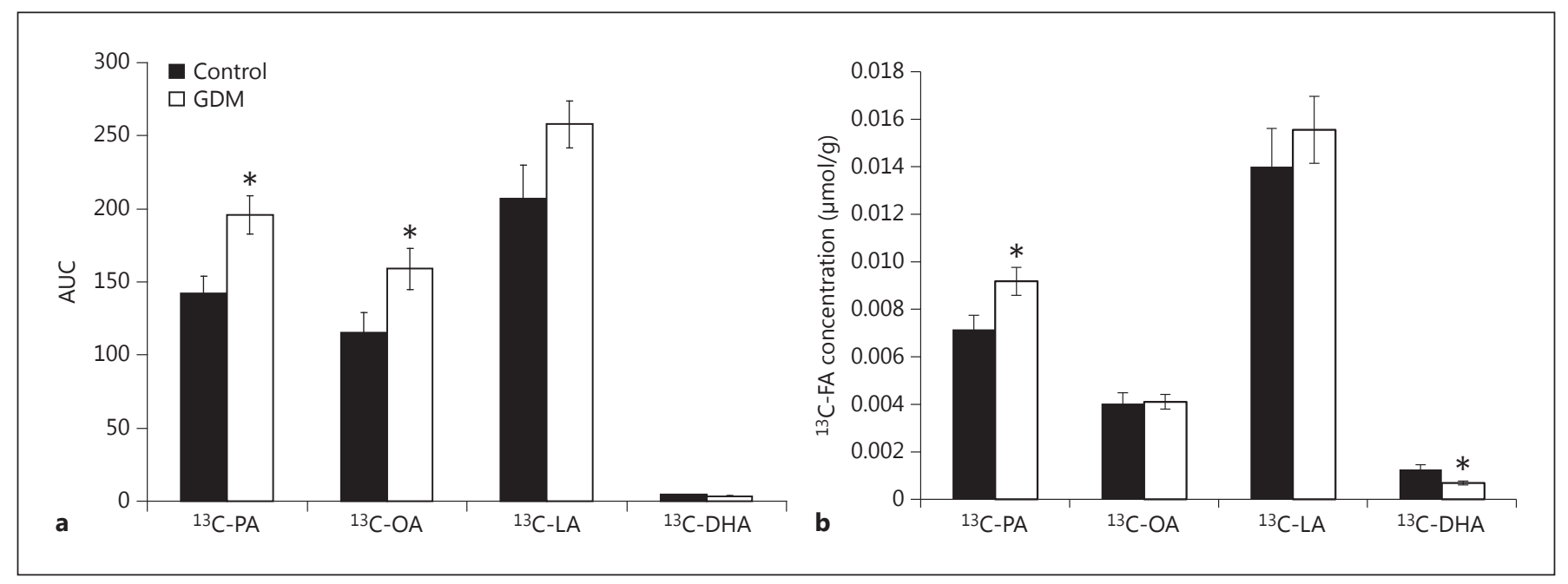

Fig. 2. a AUC of the ${ }^{13} \mathrm{C}$-FA concentration $(\mu \mathrm{mol} \cdot \mathrm{h} / \mathrm{l})$ in total lipids of maternal plasma in control and GDM subjects. b ${ }^{13} \mathrm{C}-\mathrm{FA}$ concentration in total lipids of placental tissue. ${ }^{13} \mathrm{C}-\mathrm{PA}={ }^{13} \mathrm{C}$-palmitic acid; ${ }^{13} \mathrm{C}-\mathrm{OA}={ }^{13} \mathrm{C}$-oleic acid; ${ }^{13} \mathrm{C}$-LA $={ }^{13} \mathrm{C}$-linoleic acid.
Control group, $\mathrm{n}=11$ (except for ${ }^{13} \mathrm{C}-\mathrm{DHA}$ in which $\mathrm{n}=6$ ); GDM group, $\mathrm{n}=9$. Results are expressed as means \pm SEM. ${ }^{*} \mathrm{p}<0.05$. $\mathrm{p}=0.096$ for ${ }^{13} \mathrm{C}$-LA and $\mathrm{p}=0.057$ for ${ }^{13} \mathrm{C}$-DHA. Data were taken from Pagan el al. [26].

\section{Placental Transfer of FA Labeled with Stable Isotopes in GDM}

Because placental lipid pools serve as a relay towards transport to the fetus, we studied in humans the in vivo placental transfer of FA using labeled FA with stable isotopes [26]. Eleven controls and 9 pregnant women with $\mathrm{GDM}$ received orally ${ }^{13} \mathrm{C}$-palmitic, ${ }^{13} \mathrm{C}$-oleic, and ${ }^{13} \mathrm{C}$ linoleic acids and ${ }^{13} \mathrm{C}$-docosahexaenoic acid $\left({ }^{13} \mathrm{C}\right.$-DHA) $12 \mathrm{~h}$ before an elective caesarean section. Maternal blood samples were collected at $-12,-3,-2$, and $-1 \mathrm{~h}$, at delivery, and at $+1 \mathrm{~h}$ (postdelivery), and placenta, venous, and arterial cord blood were collected at delivery.

As shown in figure $2 \mathrm{a}$, we calculated the area under the curve (AUC) of the labeled FA in maternal plasma prior to the caesarean section (corresponding to time 0 ). We observed a clear difference in AUC between ${ }^{13} \mathrm{C}$ DHA and the rest of the labeled FA in the maternal plasma of GDM subjects. The AUC of ${ }^{13} \mathrm{C}$-palmitic, ${ }^{13} \mathrm{C}$-oleic, and ${ }^{13} \mathrm{C}$-linoleic acid concentrations $(\mu \mathrm{mol} \cdot \mathrm{h} / \mathrm{l})$ were significantly higher in GDM patients compared to controls, indicating a lower plasma clearance of non-LCPUFA in GDM mothers, contributing to maternal hyperlipidemia in these subjects. In contrast, the ${ }^{13} \mathrm{C}$-DHA concentration was significantly lower in the total lipids of GDM maternal plasma at the time of delivery, and its AUC $(\mu \mathrm{mol} \cdot \mathrm{h} / \mathrm{l})$ tended to be reduced in GDM mothers $(\mathrm{p}=0.057)$.
That the maternal hyperlipidemia in GDM is mainly a hypertriglyceridemia has been indicated by the higher concentration of labeled non-LC-PUFA in the maternal plasma triglycerides of GDM patients compared to controls [26]. In type 2 diabetes, it has been reported that insulin resistance causes high postprandial levels of triglyceride-rich lipoproteins and a prolonged presence in the circulation [27]. However, ${ }^{13} \mathrm{C}$-DHA showed a lower relative incorporation into maternal plasma phospholipids in GDM, while a similar incorporation into triglycerides was seen [26]. The lipid fraction in which the FA are esterified within maternal plasma is important for their placental uptake and transfer. A disturbed incorporation of DHA in maternal plasma phospholipids could affect the plasma clearance of ${ }^{13} \mathrm{C}$-DHA and its placental uptake in this pathology. These results are in agreement with Thomas et al. [28], who suggested a potential failure to incorporate LC-PUFA into red cell phospholipids in addition to a defect in placental transport in GDM.

As occurred in maternal plasma, the concentration of labeled DHA was also reduced in total lipids of placental tissue from women with GDM. However, for the other FA investigated, and specially for palmitic acid, there was a tendency towards a higher concentration in GDM placentas, in agreement with the profile in maternal circulation (fig. 2b). In vitro studies of BeWo cells (a trophoblast cell line) treated with palmitate acid have shown that this saturated FA enhances placental lipotoxicity and changes 


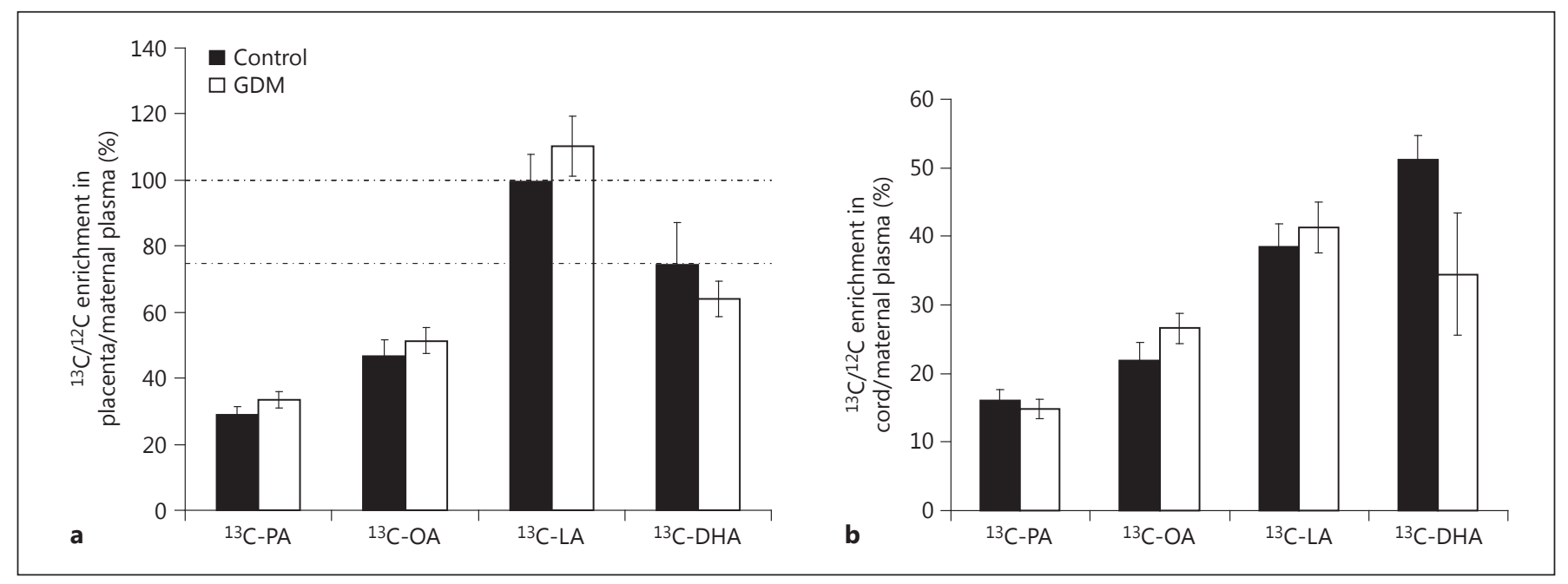

Fig. 3. a Ratio of ${ }^{13} \mathrm{C} /{ }^{12} \mathrm{C}$ enrichment in placenta vs. maternal plasma in GDM subjects. b Ratio of ${ }^{13} \mathrm{C} /{ }^{12} \mathrm{C}$ enrichment in venous cord plasma vs. maternal plasma. Results are expressed as means \pm
SEM. ${ }^{*} \mathrm{p}<0.05 . \mathrm{p}=0.187$ for ${ }^{13} \mathrm{C}-\mathrm{DHA}$ in $(\mathbf{b})$. Data were taken from Pagan et al. [26]. the chromatin structure in a manner that is permissive to subsequent increases in inflammatory cytokine gene expression [29].

The ratio between the ${ }^{13} \mathrm{C}$-FA concentration in the placenta and the ${ }^{13} \mathrm{C}$-FA concentration in maternal plasma was significantly lower for ${ }^{13} \mathrm{C}$-DHA in GDM patients compared to controls [26]. These results clearly demonstrate an impaired placental uptake of LC-PUFA in GDM placentas. The ratio between compartments calculated using concentration values of ${ }^{13} \mathrm{C}$ provides information on the species of labeled maternal FA that are transported by the placenta. Nevertheless, with stable isotope techniques it is also possible to obtain information on ${ }^{13} \mathrm{C} /{ }^{12} \mathrm{C}$ enrichment in the sample, which gives information on the dilution of the labeled FA in the pool [26]. The enrichment ratio between the placental and maternal compartments gives information on how many FA, labeled plus unlabeled, in the placenta are of maternal origin. Using the enrichment ratio between the placenta and maternal plasma, we again observed that less ${ }^{13} \mathrm{C}$-DHA in the placenta seemed to be maternally derived in GDM patients compared to normoglycemic pregnancies (in agreement with a lower placental transfer; fig. 3a). In contrast, other FA tended to show an increased transfer in GDM (fig. 3a). It is interesting to note that, for essential FA such as linoleic acid, the $100 \%$ enrichment ratio indicates that the majority of all linoleic acids in placenta are derived from maternal plasma, in agreement with the behavior of es- sential FA. For a conditionally essential FA such as DHA, the enrichment ratio in the placenta with respect to maternal plasma was about $70 \%$; thus, most of the DHA in the placenta also appeared to originate in maternal plasma, although this measurement was performed only at one time point (fig. 3a).

In cord blood, babies from GDM mothers had decreased percentages of ${ }^{13} \mathrm{C}-\mathrm{DHA}$, both in arterial and venous cord plasma, while the concentrations of other FA tended to be higher in GDM in both cord vessels, promoting fetal macrosomia [26]. Our results are in agreement with observational studies in neonates born to mothers with GDM that reported decreased percentages of DHA both in cord plasma and in cord red blood cells [28, 30,31]. The reduced ratio of ${ }^{13} \mathrm{C}$-DHA between cord and maternal plasma occurred not only when using the concentration ratio [26] but also with the enrichment ratio (fig. 3b), which is consistent with the lower absolute materno-fetal transfer of DHA in GDM. In contrast, the transfer of non-LCPUFA was not affected by GDM, tending towards higher enrichment values which could promote fetal adiposity in the offspring of GDM mothers (fig. 3b).

We could not detect any arterio-venous difference using concentration or enrichment values [26]; the high variance demonstrated by the wide standard errors, and therefore inadequate power, plecluded the possibility to find differences in fetal accretion between groups [26]. A possible limitation of the detection of differences with this 


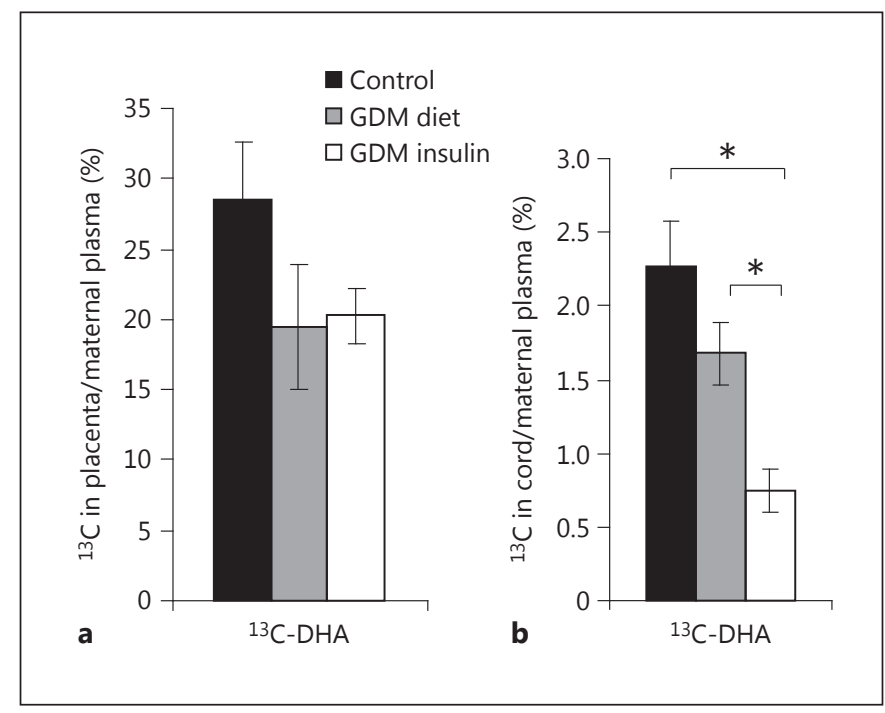

Fig. 4. a Ratio of the ${ }^{13} \mathrm{C}$-DHA concentration in placenta (nmol/g $\left.{ }^{13} \mathrm{C}\right)$ vs. maternal plasma $\left(\mu \mathrm{mol} /{ }^{13} \mathrm{C}\right)$ in $\mathrm{GDM}$ treated either with diet or with insulin. $\mathbf{b}$ Ratio of the ${ }^{13} \mathrm{C}$-DHA concentration in venous cord plasma vs. maternal plasma. Control group, $\mathrm{n}=11$; GDM diet group, $\mathrm{n}=3$; GDM insulin group, $\mathrm{n}=6$. Results are expressed as means \pm SEM. ${ }^{*} \mathrm{p}<0.05$. Data were taken from Pagan et al. [26].

methodology could be that the major differences between arteries and veins occur in the NEFA fraction, and the carbon 13 determination in NEFA is less precise than in other lipid fractions due to the low NEFA concentration in cord blood, which is difficult to measure accurately. Another possibility could be that the 12-hour experimental period was inadequate to detect differences in FA uptake by fetal tissues since, within that period of $12 \mathrm{~h}$, labeled FA have to be distributed in the maternal compartment, taken up by the placenta, released to the venous cord blood, redistributed among fetal lipoproteins, taken up by fetal tissues, and released again to the arterial cord circulation. Nevertheless, the materno-fetal transfer of ${ }^{13} \mathrm{C}$-DHA was lower in women with GDM treated with insulin compared to those treated with diet, and in both groups it was lower than in the controls (fig. 4a). In contrast, fetuses from the treatment groups had similar disturbed placental uptakes of DHA compared to controls (fig. 4b). Thus, the fetuses of GDM women treated with insulin appeared to have lower ${ }^{13} \mathrm{C}$-DHA levels in cord blood as a result of a pathway other than placental uptake (most likely a higher fat accretion by fetal adipose tissue). It is probable that maternal hyperglycemia peaks are greater in women treated with insulin, thereby producing fetal hyperinsulinemia peaks that enhance FA accretion by fetal tissues. We cannot discount a role for the higher fetal accretion of LC-
PUFA in addition to the impaired placental transfer in children from GDM mothers treated with insulin.

Concerning the effect of GDM or obesity on placental FA carriers, most studies are limited by a small sample size, which influences the interpretation of results due to the biological variability among placentas. The available results on placental lipases in GDM patients are inconclusive, maybe because of the low number of subjects; no changes [8, 32], increases in EL but not in LPL [33], increases in LPL [34], and even a reduction in placental LPL [35] in GDM have been reported.

Concerning placental FA carriers, in obese subjects without GDM, FATP-4 was also decreased while FAT/ CD36 was increased [34]. FATP may contribute to reacylation of PL because of their acyl CoA synthetase activity [36], having an additional role compared to other FA carriers. DHA is mainly located in plasma phospholipids, and FATP-4 could influence its reacylation in placental PL and its movement within the tissue [37]. Indeed FATP4 gene expression has previously been linked to selective placental transfer of n-3 LC-PUFA, since its gene expression has been found to correlate with the percentage of DHA in cord plasma PL [38]. FAT is an FA translocase that is coupled to cytosolic FABP as A-FABP. Upregulation of A-FABP in obese women with GDM has been reported and seems to have an important role in trophoblast lipid accumulation [39].

Thus, it is important to control not only glycemia but also dyslipidemia in pregnant women to avoid neonatal fat accretion and disturbed fetal LC-PUFA, which could have implications for neurodevelopment and the later risk of obesity.

\section{Acknowledgements}

This work received financial support from the Hero Institute for Infant Nutrition (Hero Spain S.A., Murcia, Spain). The studies reported herein have been carried out with partial financial support from the Commission of the European Community, within the 7th Framework Programme, research grant No. KBBE-20115-289346 (EarlyNutrition project). A.P. is the recipient of a fellowship provided by Fundación Séneca (Murcia, Spain). E.L. is a recipient of the ESPGHAN Award for Young Investigators (Budapest, 2009). B.K. is the recipient of a Freedom to Discover Award of the Bristol Myers Squibb Foundation (New York, N.Y., USA).

\section{Disclosure Statement}

None of the authors is affiliated with any advisory board or has financial or personal interests in any organization sponsoring this research. 


\section{References}

1 Pedersen J: Diabetes and pregnancy: blood sugar of newborn infants during fasting and glucose administration. Nord Med 1952;47:1049.

2 Schwartz R, Gruppuso PA, Petzold K, Brambilla D, Hiilesmaa V, Teramo KA: Hyperinsulinemia and macrosomia in the fetus of the diabetic mother. Diabetes Care 1994;17:640-648.

-3 Evers IM, de Valk HW, Mol BW, ter Braak EW, Visser GH: Macrosomia despite good glycaemic control in type I diabetic pregnancy: results of a nationwide study in the Netherlands. Diabetologia 2002;45:1484-1489.

4 Sewell MF, Huston-Presley L, Super DM, Catalano P: Increased neonatal fat mass, not lean body mass, is associated with maternal obesity. Am J Obstet Gynecol 2006;195:1100-1103.

5 Tallarigo L, Giampietro O, Penno G, Miccoli R, Gregori G, Navalesi R: Relation of glucose tolerance to complications of pregnancy in nondiabetic women. N Engl J Med 1986;315:989992.

6 Catalano PM, Farrell K, Thomas A, HustonPresley L, Mencin P, de Mouzon SH, Amini SB: Perinatal risk factors for childhood obesity and metabolic dysregulation. Am J Clin Nutr 2009; 90:1303-1313.

$>7$ Lao TT, Tam KF: Maternal serum ferritin and gestational impaired glucose tolerance. Diabetes Care 1997;20:1368-1369.

$>8$ Gauster M, Hiden U, Blaschitz A, Frank S, Lang U, Alvino G, Cetin I, Desoye G, Wadsack C: Dysregulation of placental endothelial lipase and lipoprotein lipase in intrauterine growthrestricted pregnancies. J Clin Endocrinol Metab 2007;92:2256-2263.

$>9$ Catalano PM, Presley L, Minium J, Hauguel-de Mouzon S: Fetuses of obese mothers develop insulin resistance in utero. Diabetes Care 2009; 32:1076-1080

10 Friis CM, Qvigstad E, Paasche Roland MC, Godang K, Voldner N, Bollerslev J, Henriksen T: Newborn body fat: associations with maternal metabolic state and placental size. PLoS One 2013;8:e57467.

-11 Roland MC, Friis CM, Godang K, Bollerslev J, Haugen G, Henriksen T: Maternal factors associated with fetal growth and birth weight are independent determinants of placental weight and exhibit differential effects by fetal sex. PLoS One 2014;9:e87303.

12 Clifton VL: Review: Sex and the human placenta: mediating differential strategies of fetal growth and survival. Placenta 2010;31:S33-S39.

$>13$ Illsley NP: Glucose transporters in the human placenta. Placenta 2000;21:14-22.

14 Jansson N, Rosario FJ, Gaccioli F, Lager S, Jones HN, Roos S, Jansson T, Powell TL: Activation of placental mTOR signaling and amino acid transporters in obese women giving birth to large babies. J Clin Endocrinol Metab 2013;98: 105-113.

15 Jansson T, Aye IL, Goberdhan DC: The emerging role of $\mathrm{mTORC} 1$ signaling in placental nutrient-sensing. Placenta 2012;33(suppl 2):e23e29.
16 Herrera E, Ortega-Senovilla H: Disturbances in lipid metabolism in diabetic pregnancy - are these the cause of the problem? Best Pract Res Clin Endocrinol Metab 2010;24:515-525.

17 Schaefer-Graf UM, Meitzner K, Ortega-Senovilla $H$, Graf K, Vetter K, Abou-Dakn M, Herrera E: Differences in the implications of maternal lipids on fetal metabolism and growth between gestational diabetes mellitus and control pregnancies. Diabet Med 2011;28:1053-1059.

18 Gil-Sanchez A, Koletzko B, Larque E: Current understanding of placental fatty acid transport. Curr Opin Clin Nutr Metab Care 2012;15:265272.

19 Rebholz SL, Burke KT, Yang Q, Tso P, Woollett LA: Dietary fat impacts fetal growth and metabolism: uptake of chylomicron remnant core lipids by the placenta. Am J Physiol Endocrinol Metab 2011;301:E416-E425.

20 Tewari V, Tewari A, Bhardwaj N: Histological and histochemical changes in placenta of diabetic pregnant females and its comparison with normal placenta. Asian Pac J Trop Dis 2011; $1-4$.

21 Pathmaperuma AN, Mana P, Cheung SN, Kugathas $\mathrm{K}$, Josiah A, Koina ME, Broomfield A, Delghingaro-Augusto V, Ellwood DA, Dahlstrom JE, Nolan CJ: Fatty acids alter glycerolipid metabolism and induce lipid droplet formation, syncytialisation and cytokine production in human trophoblasts with minimal glucose effect or interaction. Placenta 2010;31: 230-239.

22 Hernandez Albadalejo I, Gázquez A, Blanco JE, Parrilla JJ, Larqué E: A method for lipid droplet isolation from human placenta for further analyses in clinical trials. Acta Obstet Gynecol Scand 2014, in press.

23 Visiedo F, Bugatto F, Sanchez V, Cozar-Castellano I, Bartha JL, Perdomo G: High glucose levels reduce fatty acid oxidation and increase triglyceride accumulation in human placenta. Am J Physiol Endocrinol Metab 2013; 305:E205-E212

24 Gil-Sanchez A, Larque E, Demmelmair H, Acien MI, Faber FL, Parrilla JJ, Koletzko B: Maternal-fetal in vivo transfer of $\left[{ }^{13} \mathrm{C}\right]$ docosahexaenoic and other fatty acids across the human placenta $12 \mathrm{~h}$ after maternal oral intake. Am J Clin Nutr 2010;92:115-122.

25 Haggarty P, Ashton J, Joynson M, Abramovich DR, Page K: Effect of maternal polyunsaturated fatty acid concentration on transport by the human placenta. Biol Neonate 1999;75:350-359.

26 Pagan A, Prieto-Sanchez MT, Blanco-Carnero JE, Gil-Sanchez A, Parrilla JJ, Demmelmair H, Koletzko B, Larque E: Materno-fetal transfer of docosahexaenoic acid is impaired by gestational diabetes mellitus. Am J Physiol Endocrinol Metab 2013;305:E826-E833.

27 Pastromas S, Terzi AB, Tousoulis D, Koulouris S: Postprandial lipemia: an under-recognized atherogenic factor in patients with diabetes mellitus. Int J Cardiol 2008;126:3-12.
28 Thomas B, Ghebremeskel K, Lowy C, Min Y, Crawford MA: Plasma AA and DHA levels are not compromised in newly diagnosed gestational diabetic women. Eur J Clin Nutr 2004;58: 1492-1497.

29 Saben J, Zhong Y, Gomez-Acevedo H, Thakali KM, Borengasser SJ, Andres A, Shankar K: Early growth response protein-1 mediates lipotoxicity-associated placental inflammation: role in maternal obesity. Am J Physiol Endocrinol Metab 2013;305:E1-E14.

30 Min Y, Ghebremeskel K, Lowy C, Thomas B, Crawford MA: Adverse effect of obesity on red cell membrane arachidonic and docosahexaenoic acids in gestational diabetes. Diabetologia 2004;47:75-81

-31 Wijendran V, Bendel RB, Couch SC, Philipson EH, Cheruku S, Lammi-Keefe CJ: Fetal erythrocyte phospholipid polyunsaturated fatty acids are altered in pregnancy complicated with gestational diabetes mellitus. Lipids 2000;35: 927-931.

-32 Magnusson AL, Waterman IJ, Wennergren M, Jansson T, Powell TL: Triglyceride hydrolase activities and expression of fatty acid binding proteins in the human placenta in pregnancies complicated by intrauterine growth restriction and diabetes. J Clin Endocrinol Metab 2004;89: 4607-4614.

-33 Lindegaard ML, Damm P, Mathiesen ER, Nielsen LB: Placental triglyceride accumulation in maternal type 1 diabetes is associated with increased lipase gene expression. J Lipid Res 2006;47:2581-2588.

34 Dube E, Gravel A, Martin C, Desparois G, Moussa I, Ethier-Chiasson M, Forest JC, Giguere Y, Masse A, Lafond J: Modulation of fatty acid transport and metabolism by maternal obesity in the human full-term placenta. Biol Reprod 2012;87:14, 1-11.

35 Radaelli T, Lepercq J, Varastehpour A, Basu S, Catalano PM, Hauguel-De Mouzon S: Differential regulation of genes for fetoplacental lipid pathways in pregnancy with gestational and type 1 diabetes mellitus. Am J Obstet Gynecol 2009;201:209.e201-209.e210.

36 Coe NR, Smith AJ, Frohnert BI, Watkins PA, Bernlohr DA: The fatty acid transport protein (FATP1) is a very long chain acyl-CoA synthetase. J Biol Chem 1999;274:36300-36304.

37 Larque E, Demmelmair H, Gil-Sanchez A, Prieto-Sanchez MT, Blanco JE, Pagan A, Faber FL, Zamora S, Parrilla JJ, Koletzko B: Placental transfer of fatty acids and fetal implications. Am J Clin Nutr 2011;94:1908S-1913S.

38 Larque E, Krauss-Etschmann S, Campoy C, Hartl D, Linde J, Klingler M, Demmelmair H, Cano A, Gil A, Bondy B, Koletzko B: Docosahexaenoic acid supply in pregnancy affects placental expression of fatty acid transport proteins. Am J Clin Nutr 2006;84:853-861.

39 Scifres CM, Chen B, Nelson DM, Sadovsky Y Fatty acid binding protein 4 regulates intracellular lipid accumulation in human trophoblasts. J Clin Endocrinol Metab 2011;96:E1083-E1091. 